\title{
Carry-Over Effect of Processing Style: From Imagination Task to Recognition Task
}

\author{
Kyoko Hine ${ }^{1,2 *}$, Yuji Itoh ${ }^{1}$ \\ ${ }^{1}$ Department of Psychology, Keio University, Tokyo, Japan \\ ${ }^{2}$ RIKEN Brain Science Institute, Wako, Japan \\ Email: "hine@psy.flet.keio.ac.jp
}

Received 4 March 2016; accepted 3 June 2016; published 7 June 2016

Copyright (C) 2016 by authors and Scientific Research Publishing Inc.

This work is licensed under the Creative Commons Attribution International License (CC BY). http://creativecommons.org/licenses/by/4.0/

(c) (i) Open Access

\begin{abstract}
Accurately recognizing others' faces is very important for living successfully in the society. However, we often fail to recognize them. What causes such a problem? Numerous psychological studies reported that the performance of facial recognition was influenced by prior mental activities, so-called carry-over effect. It is considered that mental activities have two types of processing style, global processing and local processing. Global processing refers to attend the general meaning of an event. Local processing refers to attend to elements themselves. Recent studies showed that prior mental activities requiring local processing interfered with face recognition. However, it is still controversial whether or not this interference on recognition occurs only in face recognition. Here, in order to investigate if face is special for recognition, we conducted the experiments in which participants were required a prior mental activity and a following recognition task. As the prior mental activity, we used an imagination task in which participants were asked to imagine a faraway place (global processing) or a nearby place (local processing). The face and the scene picture recognition tasks were used as recognition tasks. Our results showed that the accuracy of face recognition after imagining the nearby place was worse than that after imagining the faraway place. Additionally, the same pattern was observed for scene picture recognition. The results suggest that local processing at the imagination task was carried over into not only face recognition but also scene recognition, and that local processing harmed these recognition tasks.
\end{abstract}

\section{Keywords}

Carry-Over Effect, Global/Local Processing, Face Perception, Construal Level Theory

\footnotetext{
*Corresponding author.
} 


\section{Introduction}

We encounter numerous people and events every day. Sometimes, we can recollect them accurately and at other times not. In a criminal investigation, incorrect face recollection led to a false accusation (Rattner, 1988). Thus, accurate face recollection is important in our society. There are many factors that affect the accuracy of memory recollection, especially in recognition. Recently, the processing style that is engaged before recognition is focused as one of the factors. There are two types of processing style, global and local processing (Förster \& Higgins, 2005). We attend to the general meaning of an event and relationships among its elements when we employ global processing, while we attend primarily to the elements themselves when we employ local processing (Wyer, Perfect, \& Pahl, 2010). For example, when we apply global processing at our business, we pay attention to increasing sales. When we apply local processing, we pay attention to increasing click counts on the web site, which is one of the elements that contribute to increasing sales.

A great number of psychological studies have suggested that the processing style affects the accuracy of recognition (Hills \& Lewis, 2007, 2009; Hine \& Itoh, 2014; Lewis, Mills, Hills, \& Weston, 2009; Macrae \& Lewis, 2002). For instance, Macrae and Lewis (2002) demonstrated how the Navon task influenced the performance in the subsequent face recognition task. A Navon figure (Navon, 1977) is a large letter made up of small letters (Figure 1). Reading the large letter in the Navon figure (global Navon task) requires global processing (answering “Z” in Figure 1), while reading the small letters within a Navon figure (local Navon task) requires local processing (answering “T” in Figure 1). They found that the face recognition performance after the local Navon task was lower than the performance after the global Navon task. In other words, it indicated that the processing style in the prior mental activity affected the following memory accuracy.

One of the theories that could account the mechanism of that phenomenon, which the processing style at the prior mental activity affects the memory accuracy, is the transfer-inappropriate processing shift theory (Schooler, 2002). The transfer-inappropriate processing shift theory is that the processing style engaged in the previous task was carried over into the subsequent recognition task. Figure 2 shows the processing style at the prior mental activity influences the accuracy of face recognition accounted by the transfer-inappropriate processing shift theory. It is well known that accurate face perception relies more on configural/global processing (Diamond \& Carey, 1977; Dodson, Johnson, \& Schooler, 1997; Tanaka \& Farah, 1993; Young, Hellawell, \& Hay, 1987), which refers to relationships between features, than on featural/local processing, which deals with each feature of a face (Tanaka \& Farah, 1993). In this case, when a participant engaged the local Navon task that requires local processing, local processing was carried over into the following face recognition task. Then, local processing becomes dominant in the recognition task and global processing is interfered. In that case, the accuracy of face recognition was harmed (the bottom in Figure 2).

A number of researches about the transfer-inappropriate processing shift theory examined the carry-over effect from a previous task into the following face recognition (Gao, Flevaris, Robertson, \& Bentin, 2011; Hills \& Lewis, 2007, 2008, 2009; Hine \& Itoh, 2014; Lawson, 2007; Lewis, Mills, Hills, \& Weston, 2009; Macrae \& Lewis, 2002; Perfect, 2003; Perfect, Dennis, \& Snell, 2007; Perfect, Weston, Dennis, \& Snell, 2008; Weston, Perfect, Schooler, \& Dennis, 2008; Wickham \& Lander, 2008). To check the carry-over effect, the imagination task required participants to imagine their future was used in some studies (Hunt \& Carroll, 2008; Wyer, Perfect, \& Pahl, 2010). The rationale for enlisting the imagination task to investigate the carry-over effect on face

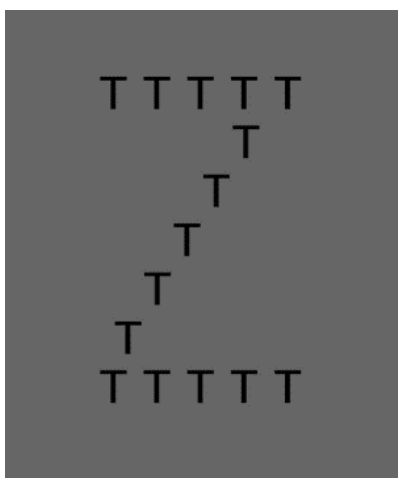

Figure 1. A sample of a Navon figure. 


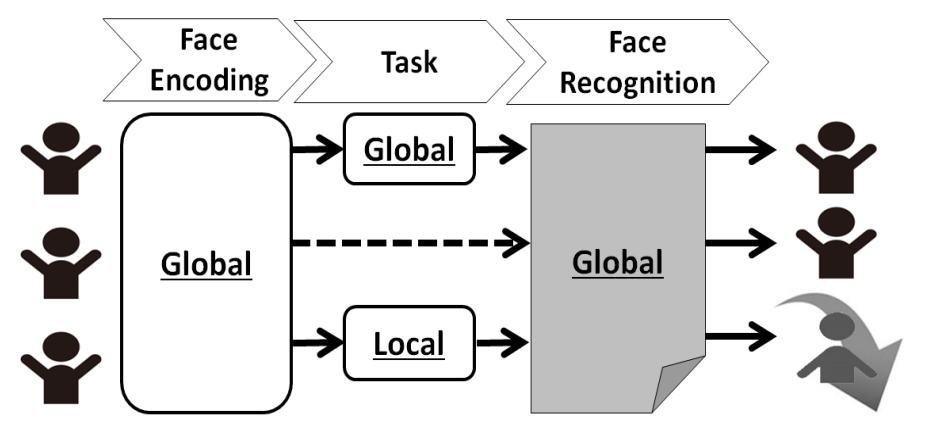

Figure 2. A diagram about the improvement of face recognition accounted by the transfer-inappropriate processing shift theory.

recognition derives from Construal Level Theory (Liberman \& Trope, 1988). In Construal Level Theory, it is assumed that abstraction is involved in mental construal. Mental construal in higher-levels is regarded as abstract and schematic processing whereas mental construal in lower-levels is considered as concrete processing (Liberman \& Trope, 2008). The imaginative mental representation involved in higher-level construal includes super-ordinate and core features. By contrast, the imaginative mental representation required for lower-level construal includes subordinate and incidental features. For example, “playing tennis” is represented abstractly as simply "having fun" when considered as higher-level construal. On the other hand, in lower-level construal, the same activity involves something concrete such as players and tools used in tennis. In short, the former is more abstract than the latter. Therefore, we here could consider that thinking abstractly relates global processing and thinking concretely relates local processing.

Recently, it was reported that psychological distance has affected construal level (Liberman \& Trope, 1998; Trope \& Liberman, 2000). In those previous studies, people are likely to think about something abstract when they imagine their far futures. On the other hand, when we imagine our near futures, we tend to think about something concrete. In other words, thinking about far future induces global processing style whereas thinking about near future induces local processing style.

Some researches reported the effect of distance to an imagined future on face recognition (Hunt \& Carroll, 2008; Wyer, Perfect, \& Pahl, 2010). Wyer, Perfect, and Pahl (2010) investigated the effect of imagining the future on face recognition. In their study, participants had a conversation with a target person for two minutes, i.e., an encoding phase. After the conversation, participants in the distant future condition were required to imagine themselves on five or six months in the future. Participants in the near future condition had to imagine themselves on the next day. Next, all participants identified the target face in a line-up that included eight faces. The identification accuracy for the near future condition was lower than that for the distant future condition. According to Construal Level Theory, local processing should be more involved in imagining the near future than in imagining the distant future. The Wyer et al. findings are consistent with this interpretation by suggesting that local processing in the imagination task is carried over and interferes with the face recognition performance.

Although previous studies (Hunt \& Carroll, 2008; Wyer, Perfect, \& Pahl, 2010) have suggested that the processing style in the imagination task affects the accuracy of face recognition, there is still a controversy whether or not this effect is found only in face recognition. Several studies insisted that face recognition is special function (Cassia, Picozzi, Kuefner, Bricolo, \& Turati, 2008; Curby, Glazek, \& Gauthier, 2009; Gauthier \& Logothetis, 2000; Gauthier, Skudlarsiki, Gore, \& Anderson, 2000; Xu, Liu, \& Kanwisher, 2005). Therefore, one might expect that the imagination task affects only face recognition. On the other hand, the transfer-inappropriate processing shift theory is adapted to nonverbal recognition including face and visual picture (Brown \& Lloyd-Jones, 2002; Melcher \& Schooler, 2004). Thus, the impact of the imagination task should be observed both on face and visual picture recognition if the transfer-inappropriate processing shift theory could account the phenomenon that the imagination task affects the performance of the following recognition task. This means that face and scene picture recognition would share some common mechanism. In the current study, to investigate specificity of face recognition, we assessed the impact of the imagination task on not only face recognition but also scene picture recognition.

Additionally, for checking the validity of psychological distance effect, we examined the effect of the spatial distance of the imagination task on subsequent face recognition instead of the temporal distance. According to 
Construal Level Theory, the spatial distance also influences the construal level. Therefore, in our experiments, imaging a nearby place is predicted to lower performance in a subsequent facial recognition test relative to imaging a faraway place.

We investigated whether or not local processing at the prior mental activity affects only the facial recognition task. We conducted group experiments. In Experiment 1, to assess the carry-over effect from an imagination task to a face recognition task, we used facial photos. It was expected that the accuracy of face recognition after imagining a nearby place is lower than that after imagining a faraway place. In Experiment 2, to assess the carryover effect from an imagination task to a non-face recognition task, we used pictures of clouds (Itoh et al., 2009). If the transfer-inappropriate processing shift theory could account the phenomenon that an imagination task affects a performance of a following face recognition task, it was also predicted that the accuracy of scene picture recognition after imagining a nearby place is lower than that after imagining a faraway place.

\section{Experiment 1}

\subsection{Method}

\subsubsection{Participants}

Sixty-four participants aged 19 - 20 years $\left(M_{\text {age }}=19.0\right.$ years) took part in Experiment 1 . Participants were students of a university located in Omiya city that is near Tokyo. Participants were randomly assigned to a nearby place condition (7 women and 15 men), a faraway place condition ( 8 women and 13 men), and a control condition (5 women and 16 men).

\subsubsection{Materials}

A video depicted an Asian male suspect stealing money from a bag after entering a room. The room had one entrance without a door. There was a counter of a PC rental in the room. One PC and one handbag were on the desk of the counter. At the beginning of the video, nobody show on the video. Then, a male entered in the room. The male asked a reception female to lend a PC. The reception female did not show on the video, but her voice was heard. She said "Just moment". While she went to the inside to pick up a PC, the male looked around, picked up some money from the handbag on the desk, and then inserted money in the pocket on his jacket. After that, her voice "Here you go" was heard. The male received the PC, and went out of the room. Finally, nobody was shown in the video, and the video was over. The video lasted $31 \mathrm{~s}$. No other persons appeared on the video.

A face-photo lineup was prepared for the face recognition task. The photo lineup consisted of six frontal color photographs arranged in a $3 \times 2$. All were full faces with neutral facial expressions. Each person in the lineup was Asian, and matched the same gender and the general physical description as the culprit.

Two kinds of booklets were used for Experiment 1. One booklet was for the imagination task and the other was for the recognition task. There were three types of booklets for the imagination task, for the nearby place, the faraway place, and the control condition. Booklets for the imagination task contained instructions and a section for participants to write their answers. Booklets for the recognition task had two pages. The first page was an answer section for the recognition task; the second page is a questionnaire about the recognition task.

\subsubsection{Procedure}

Experiment 1 was conducted during a psychology class. Participants viewed the video depicting a crime. Participants were not told that they would take a face recognition test later. The video was projected on a screen in front of the classroom.

After watching the video, participants randomly took one of the three booklets for the imagination task. Instructions printed on the booklet for the nearby place condition were "Imagine what you are doing in Omiyacity, 7 kilometers away from here, and write this down." in Japanese. Instructions for the faraway place condition booklet were "Imagine what you are doing in London, 9500 kilometers away from here, and write this down." in Japanese. The booklets for the nearby and the faraway place condition also contained instructions that stated that participants did not need to base their writing on a specific person and could freely imagine any situations. The booklet for the control condition contained two types of questions: one was about the combination of administrative divisions and the seat of Prefectural governments, and another was a questionnaire about the combination of countries and capitals. For example, when "Hokkaido-" is given, the correct answer is "Sapporo". (Hokkaido is one of administrative divisions in Japan, and Sapporo is the seat of Prefectural government of 
Hokkaido.) The number of questions for the control condition was ninety-five. The experimenter also read out the instructions for the nearby place, the faraway place and the control condition. It took five minutes for giving the instructions. Participants engaged in the imagination task or in answering the questions for five minutes. Then, the booklets were turned back to the experimenter.

Finally, the booklets for the recognition task were passed out to the all participants. The face-photo lineup was presented in one slide on a screen. The target presented on the upper right. Participants were asked to choose the face of the suspect in the video from those six faces. Participants were also required to rate their confidences in their choices on a scale from 1 (uncertain) to 7 (certain).

After they chose one face and gave the confidence ratings, they answered the questions about the recognition task. The three questions were as follows: "How difficult was the recognition task?", "How long would you estimate that the suspect stayed in the classroom?", and "How long would you estimate that you saw the suspect?" In the first question, participants chose on a scale from 1 (very easy) to 7 (very difficult). In the second and the third questions, participants answered with unit of second. After the experimenter ensured that all the participants finished answering the questions, the booklets for the recognition task were submitted. Participants were then thanked and debriefed.

\subsection{Results}

\subsubsection{Language Use}

Written descriptions in the nearby and the faraway place conditions were analyzed for abstractness of language using the Linguistic Categorization Model (Semin \& Fielder, 1988). A participant's description of events in a far future should contain more abstract terms than a description of a near future situation (Semin \& Smith, 1999). Each clause was coded as belonging to one of four linguistic categories, DAV, IAV, SV, and ADJ. DAV is a descriptive action verb, which is the most concrete category and provides an objective description of a specific behavioral event. For example, "hit", "yell”, and "walk" are included in DAV. IAV is an interpretive action verb, which is a general verb. "Help", "tease”, and "avoid" are included in IAV. SV is stative verb, which expresses a mental and an emotional state about a specific object. "Admire", "hate", and "appreciate" are included in SV. ADJ is adjective, which expresses a personality. "Honest”, "reliable”, and "aggressive” are included in ADJ. Semin and Fiedler reported that DAV is the most concrete category and ADJ is the most abstract one. After the categorization, each clause that was categorized to one of four categories was given an index. The index was 1 , 2, 3, and 4, which reflects DAV, IAV, SV, and ADJ respectively (Semin \& Smith, 1999). These indexes were used for statistical analyses of abstractness in all clauses. The example of DAV that was written in the current study was "I am walking". The example of IAV was "I am traveling".

Written descriptions in the nearby and the faraway place conditions were analyzed for linguistic abstractness. We confirmed that participants in the faraway place condition $(M=1.70)$ used a greater amount of abstract languages than those in the nearby place condition $(M=1.37), t(39)=2.64, p=.01, r=.39$.

\subsubsection{Rates of Correct Recognition}

The mean rates of correct face recognition were $63.6 \%$ for the nearby place condition, $81.0 \%$ for the faraway place condition and $100.0 \%$ for the control condition. There was the comparable correct recognition rate across the three conditions $\left(\chi^{2}(2, N=64)=9.33, p<.01\right.$, Cramer's $\left.V=.27\right)$.

\subsubsection{Combination Score}

Combination scores were calculated for each participant. This combination score has a range of -7 to 7 . When a subject made a correct choice, the combination score was the same as the confidence rate. When a subject made an incorrect choice, the combination score was a negative number corresponding to the confidence rate. This scoring technique followed that of Westerman and Larsen (1997). It is known that the combination score and the rate of correct recognition show the same general pattern (Dodson, Johnson, \& Schooler, 1997). It has also been reported that group differences were more apparent with the combination score (Dodson, Johnson, \& Schooler, 1997).

Figure 3 shows the means of the combination score. The mean of the combination score in the nearby place condition was $1.05(S D=4.96)$. The mean of the combination score in the faraway place condition was 3.91 ( $S D$ $=3.93$ ) whereas the mean of this score for the control condition was $5.81(S D=1.18)$. A one-way ANOVA was 


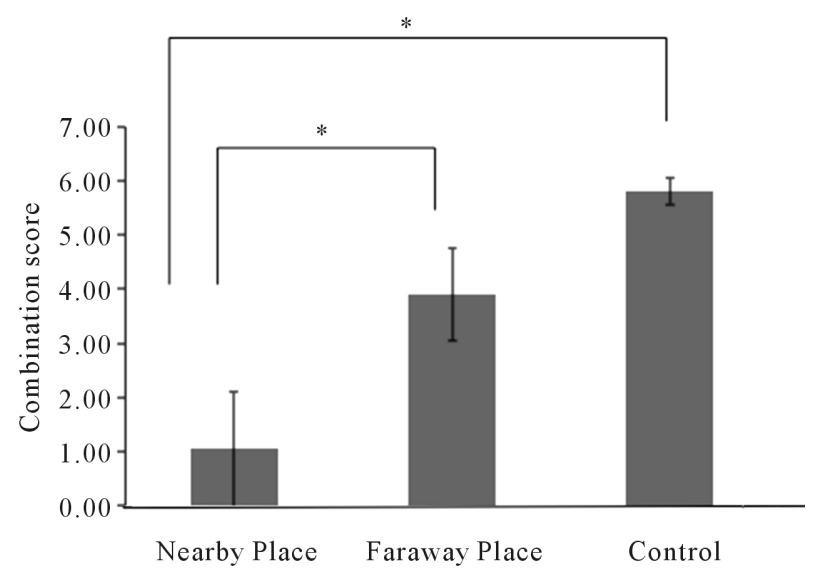

Figure 3. Means of combination score for the nearby place, the faraway place and the control conditions in Experiment 1. Error bars represent standard errors. When subjects made a correct choice, the combination score was the same as the confidence rate. When subjects made an incorrect choice, the combination score was a negative number corresponding to the confidence rate.

conducted on the combination score. The main effect of the imagination task was significant, $F(2,61)=8.46$, $M S E=123.93, p<.01$, partial $\eta^{2}=.22$. Further statistical analyses, using Bonferroni method, were conducted. The combination score in the nearby place condition was significantly lower than that in the faraway place condition $(p<.05)$. In addition, the combination score in the nearby place condition was significantly lower than that observed in the control condition $(p<.05)$. The combination score in the faraway place condition did not differ significantly from that in the control condition.

\subsubsection{Evaluation of Difficulty of the Recognition Task}

The mean of the difficulty score of the recognition task in the nearby place condition was $4.05(S D=1.64)$. The mean of the score in the faraway place condition was $4.00(S D=1.46)$. The mean of the score in the control condition was $4.62(S D=1.33)$. A one-way ANOVA was conducted on the difficulty score of the recognition task indicated that the main effect of the distance in the imagination task was not significant, $F(2,61)=1.10$, $M S E=2.52, p=.34$, partial $\eta^{2}=.04$.

\subsubsection{Estimated Time of the Target Person's Presence}

The time that participants estimated for how long the culprit stayed in the room was analyzed. The average of estimated time of the culprit's presence in the nearby place condition was 25.09 seconds $(S D=17.75)$ whereas the average of estimations of this time in the faraway place condition was 28.81 seconds $(S D=29.35)$. In the control condition, this average was 30.48 seconds $(S D=12.61)$. A one-way ANOVA was conducted on the estimated staying time of the culprit staying. There was not a significant main effect of the imagination task, $F(2$, 61) $=0.35, M S E=164.16, p=.70$, partial $\eta^{2}=.01$.

\subsubsection{Estimated Time of Observing the Target Person}

Participants' estimates of how long they observed the culprit were also analyzed. The average of estimated observing time in the nearby place condition was 8.05 seconds $(S D=6.93)$ whereas the average of the time in the faraway place condition was 10.33 seconds $(S D=7.82)$. In the control condition, this estimate averaged 14.10 seconds $(S D=10.07)$. A one-way ANOVA was conducted on the estimated observing time. The main effect of the imagination task was marginally significant, $F(2,61)=2.73, M S E=199.75, p=.07$, partial $\eta^{2}=.08$. Follow-up analyses, using the Bonferroni method, were conducted. The estimated observing time in the nearby place condition was significantly lower than that in the control condition $(p<.05)$. No significant difference emerged either between the times in the faraway place condition and the control condition or between estimated observing times in the nearby place condition and the faraway place condition. An analysis of covariance 
(ANCOVA) with the estimated observing time as covariate was conducted on the combination score because there was a possibility that how long participants paid attention to the target face might affect their face recognition performances. The main effect of the imagination task was still significant, $F(2,58)=3.97, M S E=59.34$, $p=.02$, partial $\eta^{2}=.10$. This result suggests that the main effect of the imagination task in the combination score remained significant even when the effect of the estimated observing time was controlled.

\subsection{Discussion}

The aim of Experiment 1 was to assess the effect of the spatial distance of imagination on face recognition. The combination score in the nearby place condition was lower than that in the faraway place condition. The results of Experiments 1 suggest that the abstractness of imagination increases with imagined psychological distance, and the cognitive processing style of abstractness carried over into face recognition. This carry-over affected the performance of the face recognition task in that participants were less accurate in facial recognition following imagined the nearby place than following imagined the faraway place, suggesting that local processing evoke during the imagination task (in the nearby place condition) is carried over and interferes with configural/global processing of faces in the recognition task.

\section{Experiment 2}

\subsection{Method}

\subsubsection{Participants}

One hundred twenty three participants aged 19 - 43years $\left(M_{\text {age }}=19.3\right.$ years) took part in Experiment 2. Participants were students of a university located in Omiya city. Participants were randomly assigned to a nearby place condition (12 women and 26 men), a faraway place condition (11 women and 29 men), and a control condition (12 women and 33 men).

\subsubsection{Materials}

Six pictures of clouds were prepared (Figure 4). The pictures were identical as that used in Itoh et al. (2009). One of the six pictures was prepared as a target (Figure 4(a)). The photo presenting clouds including the target and non-targets were of the same part of the sky and were taken successively with few second intervals. The same as Experiment 1, two kinds of booklets were used in Experiment 2, the imagination task, and the recognition task.

\subsubsection{Procedure}

Experiment 2 was also conducted during a psychology class. Participants viewed a picture of clouds in the sky (Figure 4(a)) for five seconds. Participants were not told that they would take a recognition test later. The photo was projected on a screen in front of the classroom.

After viewing the picture, participants were asked to do the imagination task or to answer the questions that were the same tasks conducted in Experiment 1. Finally, participants took a recognition task. Six pictures of

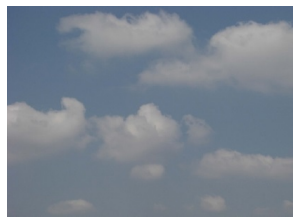

(a)

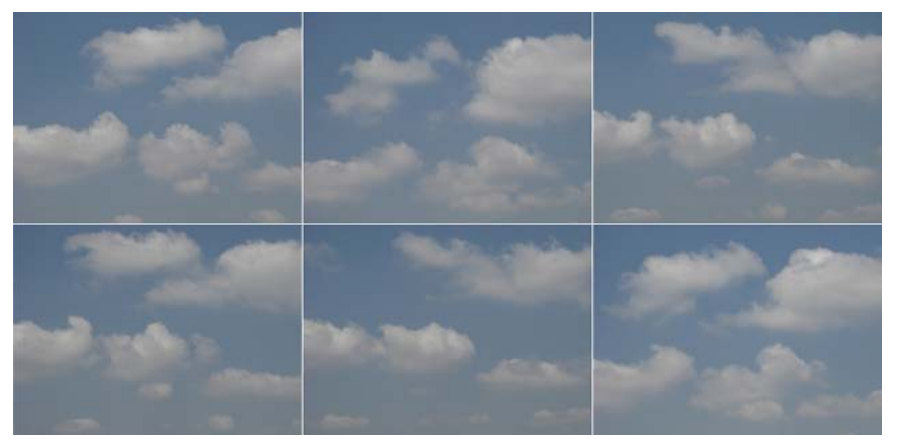

(b)

Figure 4. Scene pictures used in Experiment 2. (a) A target photo for the recognition task; (b) The six photos showed in the recognition task. 
clouds were presented in one slide on a screen, arranged in a $3 \times 2$ matrix (Figure 4(b)). Participants were required to choose the photo in the previously seen from these six clouds photos. Participants were also asked to rate their confidences in their choices on a scale from 1(uncertain) to 7 (certain).

After they chose one picture and gave the confidence ratings, they answered the questions about the recognition task. The questions were as follows: "How difficult was the recognition task?" and "How long would you estimate that you saw the picture at first?" After the experimenter ensured that all the participants finished answering the questions, the booklets for the recognition task were submitted. Participants were then thanked and debriefed.

\subsection{Results}

\subsubsection{Language Use}

Written descriptions in the nearby and the faraway place conditions were analyzed for linguistic abstractness the same as in Experiment 1. Participants in the faraway place condition $(M=1.89)$ used a greater amount of abstract languages than those in the nearby place condition $(M=1.68), t(76)=2.25, p=.01, r=.25$.

\subsubsection{Rates of Correct Recognition}

The mean rates of correct recognition were $34.2 \%$ for the nearby place condition, $62.5 \%$ for the faraway place condition and $48.9 \%$ for the control condition. There was the comparable correct recognition rate across the three conditions $\left(\chi^{2}(2, N=123)=6.24, p=.04\right.$, Cramer's $\left.V=.16\right)$.

\subsubsection{Combination Score}

Figure 5 shows the means of combination score. The mean of the combination score in the nearby place condition was $-0.76(S D=5.01)$. The mean of the combination score in the faraway place condition was $2.00(S D=$ 4.47 ) whereas the mean of this score for the control condition was $0.47(S D=4.91)$. A one-way ANOVA was conducted on the combination score. The main effect of the imagination task was significant, $F(2,120)=3.21$, $M S E=74.89, p=.04$, partial $\eta^{2}=.05$. Further statistical analyses, using Bonferroni method, were conducted. The combination score in the nearby place condition was significantly lower than that in the faraway place condition $(p<.05)$. The combination score in the control condition did not differ significantly from that in the nearby and the faraway place condition.

\subsubsection{Evaluation of Difficulty of the Recognition Task}

The mean of the difficulty score of the recognition task in the nearby place condition was $3.58(S D=1.90)$. The mean of the score in the faraway place condition was $3.63(S D=1.78)$. The mean of the score in the control

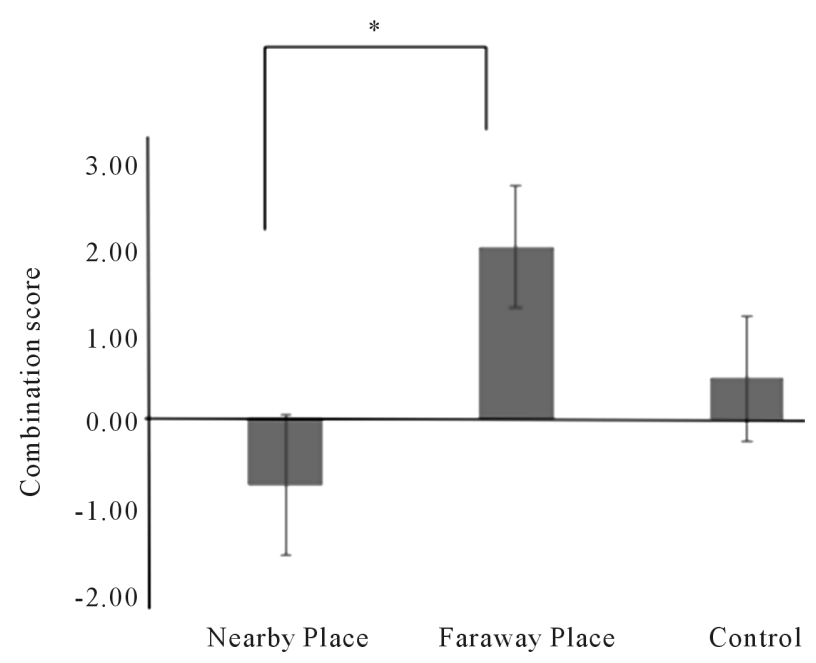

Figure 5. Means of combination score for the nearby place, the faraway place and the control conditions in Experiment 2. Error bars represent standard errors. 
condition was $3.58(S D=1.63)$. A one-way ANOVA was conducted on the difficulty score indicated that the main effect of the distance in the imagination task was not significant, $F(2,120)=.01$, MSE $=.03, p=.99$, partial $\eta^{2}=.00$.

\subsubsection{Estimated Time of Observing the Cloud Photo}

Participants' estimates of how long they observed the cloud photo at first were also analyzed. The average of estimated observing time in the nearby place condition was 10.00 seconds $(S D=11.44)$ whereas the average of the time in the faraway place condition was 9.08 seconds $(S D=7.47)$. In the control condition, this estimate averaged 11.11 seconds $(S D=9.94)$. A one-way ANOVA was conducted on the estimated observing time. The main effect of the imagination task was not significant, $F(2,120)=.46, M S E=43.59, p=.63$, partial $\eta^{2}=.00$.

\subsection{Discussion}

The aim of Experiment 2 was to assess whether or not the imagination task affected the performance of the scene picture recognition. The same as the face recognition task, imagining the nearby place interfered with the following scene recognition task. Therefore, it indicated that the dominant processing style in the imagination task was carried over into scene picture recognition the same as face recognition.

\section{General Discussion}

The aim of the current study is to investigate whether or not local processing at the prior mental activity affected only the facial recognition task. We found two important results. First, the accuracies of the face and the scene recognition tasks after imagining the nearby place were lower than those after imagining the faraway place. In other words, the influence of the imagination task was observed both in the face and the scene picture recognition tasks. The transfer-inappropriate processing shift theory expects that both face and scene picture recognition are affected by the imagination task. This expectation was supported by the results of the current study. Considerable studies reported that face recognition appears to rely mainly upon configural/global processing, while non-face recognition may not require configural processing (Cassia, Picozzi, Kuefner, Bricolo, \& Turati, 2008; Curby, Glazek, \& Gauthier, 2009; Gauthier \& Logothetis, 2000; Gauthier, Skudlarsiki, Gore, \& Anderson, 2000; $\mathrm{Xu}$, Liu, \& Kanwisher, 2005). On the other hand, other studies represent a persisting claim that configural processing is not unique to face perception (Behrmann, Avidan, Marotta, \& Kimchi, 2005; Bouvet, Rousset, Valdois, \& Donnadieu, 2011; Gauthier \& Tarr, 1997). If configural/global processing is involved in only face recognition, imagining the nearby place should harm face recognition but not harm scene picture recognition. However, this was not found in our study. Therefore, it has suggested that there is some mutual processing on face and scene picture recognition. The result might support the assertion that configural/global processing in facial perception has general processing that used in other domain processing.

Second, the spatial distance of the imagination task affected performances of the recognition tasks. Some previous studies showed the effect of the temporal distance to an imagined future on face recognition (Hunt \& Carroll, 2008; Wyer, Perfect, \& Pahl, 2010). This was predicted by Construal Level Theory (Liberman \& Trope, 1988). Construal Level Theory also predicted the effect of the spatial distance of the imagination task on face recognition. Our results supported this prediction. Therefore, it was confirmed that psychological distance affected the subsequent recognition. The effect of subjective difficulty is also a possible account of the carry-over effect. Subjective difficulty is an individual feeling of difficulty of a task (Hine, Nouchi, \& Itoh, 2011). Hine, Nouchi, and Itoh (2011) reported that subjective difficulty of a task could affect face recognition, and insisted that global processing is more involved in face recognition when subjective difficulty is higher. If participants in the nearby place condition felt less difficult than participants in the faraway place and the control condition, the accuracy of the nearby place condition was worse than that of other conditions. However, the evaluation of the difficulty of the recognition task in the nearby place condition was not lower than the faraway place condition and the control condition. Therefore, the effect of subjective difficulty could not account the results of the current study. Other alternative account was the effect of the time of looking the video or the picture. The longer duration of encoding time is, the greater the performance of face recognition is (Laughery, Alexander, \& Lane, 1971). Based on that, one might think that the performance of the memory task should be boosted if participants looked the video or the picture longer. However, the estimated time of the target person's presence was not different among the three conditions. Therefore, the duration of the encoding target face was hard to explain the 
current result. The duration of the looking of the target face should also affect the accuracy of the face recognition. It was reported that paying attention to a face boosted the accuracy of the face recognition task (Cutler, Penrod, \& Martens, 1987). Therefore, when participants pay attention to the target face for a longer time, the performance of face recognition might improve. The result of ANCOVA with the estimated time of observing the target person as covariant indicated that the effect of the imagination task was still significant in Experiment 1. Hence, the difference of participants pay attention could not account the difference of the accuracy of the face recognition. Taken all together, we could say that the psychological distance influenced the subsequent recognition task.

While these data are important for fundamental science, there is also an important suggestion for applied settings. For example, occasionally, inaccurate face recognition was accepted as an eyewitness testimony, and the inaccurate eyewitness testimony led to a false accusation (Rattner, 1988). Our study showed that the processing style affected the accuracies of the following face and the scene picture recognition tasks. Based on the current study, thinking abstractly (e.g. imagining one's faraway place) before getting an eyewitness testimony may be reasonable for keeping away from false recognition. Our study might shed light on avoiding this kind of tragedy.

\section{Acknowledgements}

This research was supported by Keio University’s Global Center of Excellence Program.

\section{References}

Behrmann, M., Avidan, G., Marotta, J. J., \& Kimchi, R. (2005). Detailed Exploration of Face-Related Processing in Congenital Prosopagnosia: 1. Behavioral Findings. Journal of Cognitive Neuroscience, 17, 1130-1149. http://dx.doi.org/10.1162/0898929054475154

Bouvet, L., Rousset, S., Valdois, S., \& Donnadieu, S. (2011). Global Precedence Effect in Audition and Vision: Evidence for Similar Cognitive Styles across Modalities. Acta Psychologica, 138, 329-335. http://dx.doi.org/10.1016/j.actpsy.2011.08.004

Brown, C., \& Lloyd-Jones, T. (2002). Verbal Overshadowing of Multiple Face and Car Recognition: Effects of Within- versus Across-Category Verbal Descriptions. Applied Cognitive Psychology, 17, 183-201. http://dx.doi.org/10.1002/acp.861

Cassia, V. M., Picozzi, M., Kuefner, D., Bricolo, E., \& Turati, C. (2008). Holistic Processing for Faces and Cars in PreschoolAged Children and Adults: Evidence from the Composite Effect. Developmental Science, 12, 236-248. http://dx.doi.org/10.1111/j.1467-7687.2008.00765.x

Curby, K. M., Glazek, K., \& Gauthier, I. (2009). A Visual Short-Term Memory Advantage for Objects of Expertise. Journal of Experimental Psychology: Human Perception and Performance, 35, 94-107. http://dx.doi.org/10.1037/0096-1523.35.1.94

Cutler, B. L., Penrod, S. D., \& Martens, T. K. (1987). The Reliability of Eyewitness Identification: The Role of System and Estimator Variables. Law and Human Behavior, 11, 223-258. http://dx.doi.org/10.1007/BF01044644

Diamond, R., \& Carey, S. (1977). Developmental Changes in the Representation of Faces. Journal of Experimental Child Psychology, 23, 1-22. http://dx.doi.org/10.1016/0022-0965(77)90069-8

Dodson, C. S., Johnson, M. K., \& Schooler, J. W. (1997). The Rate of False Source Attributions Depends on How Questions Are Asked. American Journal of Psychology, 106, 541-557. http://dx.doi.org/10.2307/1422968

Förster, J., \& Higgins, E. T. (2005). How Global versus Local Perception Fits Regulatory Focus. Psychological Science, 16, 631-636. http://dx.doi.org/10.1111/j.1467-9280.2005.01586.x

Gao, Z., Flevaris, A. V., Robertson, L. C., \& Bentin, S. (2011). Priming Global and Local Processing of Composite Faces: Revisiting the Processing-Bias Effect on Face Perception. Attention, Perception, \& Psychophysics, 73, 1477-1486. http://dx.doi.org/10.3758/s13414-011-0109-7

Gauthier, I., \& Logothetis, N. K. (2000). Is Face Recognition Not So Unique after All? Cognitive Neuropsychology, 17, 125142. http://dx.doi.org/10.1080/026432900380535

Gauthier, I., \& Tarr, M. J. (1997). Becoming a “Greeble” Expert: Exploring Mechanisms for Face Recognition. Vision Research, 37, 1673-1682. http://dx.doi.org/10.1016/S0042-6989(96)00286-6

Gauthier, I., Skudlarski, P., Gore, J. C., \& Anderson, A. W. (2000). Expertise for Cars and Birds Recruits Brain Areas Involved in Face Recognition. Nature Neuroscience, 3, 191-197. http://dx.doi.org/10.1038/72140

Hills, P., \& Lewis, M. B. (2007).Temporal Limitation of Navon Effect on Face Recognition. Perceptual and Motor Skills, 104, 501-509. http://dx.doi.org/10.2466/pms.104.2.501-509 
Hills, P., \& Lewis, M. B. (2008). Testing Alternatives to Navon Letters to Induce a Transfer-Inappropriate Processing Shift in Face Recognition. European Journal of Cognitive Psychology, 20, 561-576. http://dx.doi.org/10.1080/09541440701728524

Hills, P., \& Lewis, M. B. (2009). A Spatial Frequency Account of the Detriment That Local Processing of Navon Letters Has on Face Recognition. Journal of Experimental Psychology: Human Perception and Performance, 35, 1427-1442. http://dx.doi.org/10.1037/a0015788

Hine, K., \& Itoh, Y. (2014). Carry-Over Effects in Face Recognition: Processing Mode or Attentional Window? Journal of Cognitive Psychology, 26, 98-109. http://dx.doi.org/10.1080/20445911.2013.845193

Hine, K., Nouchi, R., \& Itoh, Y. (2011). Influence of Subjective Difficulty on the Degree of Configural and Featural Processing in Face Recognition. Japanese Psychological Research, 53, 246-257. http://dx.doi.org/10.1111/j.1468-5884.2011.00468.x

Hunt, C., \& Carroll, M. (2008). Verbal Overshadowing Effect: How Temporal Perspective may Exacerbate or Alleviate the Processing Shift. Applied Cognitive Psychology, 22, 85-93. http://dx.doi.org/10.1002/acp.1352

Itoh, Y., Sasaki, R., Hisamatsu, T., Tachi, M., Chin, J., \& Schooler, J. (2009). The Verbal Overshadowing Effect in Memory for Pictures. In S. Watanabe (Ed.), CARLS Series of Advanced Study of Logic and Sensibility (pp. 233-246). Tokyo: Keio University.

Laughery, K. R., Alexander, J. F., \& Lane, A. B. (1971). Recognition of Human Face: Effects of Target Exposure Time, Target Position, and Type of Photograph. Journal of Applied Psychology, 59, 460-496.

Lawson, R. (2007). Local and Global Processing Biases Fail to Influence Face, Object, and Word Recognition. Visual Cognition, 15, 710-740. http://dx.doi.org/10.1080/13506280601112519

Lewis, M. B., Mills, C., Hills, P. J., \& Weston, N. (2009). Navon Letters Affect Face Learning and Face Retrieval. Experimental Psychology, 56, 258-264. http://dx.doi.org/10.1027/1618-3169.56.4.258

Liberman, N., \& Trope, Y. (1998). The Role of Feasibility and Desirability Considerations in Near and Distant Future Decisions: A Test of Temporal Construal Theory. Journal of Personality and Social Psychology, 75, 5-18. http://dx.doi.org/10.1037/0022-3514.75.1.5

Liberman, N., \& Trope, Y. (2008). The Psychology of Transcending the Here and Now. Science, 322, 1201-1205. http://dx.doi.org/10.1126/science.1161958

Macrae, C. N., \& Lewis, H. L. (2002). Do I Know You? Processing Orientation and Face Recognition. Psychological Science, 13, 194-196. http://dx.doi.org/10.1111/1467-9280.00436

Melcher, J. M., \& Wchooler, J. W. (2004). Perceptual and Conceptual Training Mediate the Verbal Overshadowing Effect in an Unfamiliar Domain. Memory \& Cognition, 32, 618-631. http://dx.doi.org/10.3758/BF03195853

Navon, D. (1977). Forest before the Trees: The Precedence of Global Features in Visual Perception. Cognitive Psychology, 9, 353-383. http://dx.doi.org/10.1016/0010-0285(77)90012-3

Perfect, T. J. (2003). Local Processing Bias Impairs Lineup Performance. Psychological Reports, 93, 393-394.

Perfect, T. J., Dennis, I., \& Snell, A. (2007). The Effects of Local and Global Processing Orientation on Eyewitness Identification Performance. Memory, 15, 784-798. http://dx.doi.org/10.1080/09658210701654627

Perfect, T. J., Weston, N. J., Dennis, I., \& Snell, A. (2008). The Effects of Precedence on Navon-Induced Processing Bias in Face Recognition. The Quarterly Journal of Experimental Psychology, 61, 1479-1486.

http://dx.doi.org/10.1080/17470210802034678

Rattner, A. (1988). Convicted but Innocent: Wrongful Conviction and the Criminal Justice System. Law and Human Behavior, 12, 283-293. http://dx.doi.org/10.1007/BF01044385

Schooler, J. W. (2002). Verbalization Produces a Transfer Inappropriate Processing Shift. Applied Cognitive Psychology, 16, 989-997. http://dx.doi.org/10.1002/acp.930

Semin, G. R., \& Fiedler, K. (1988). The Cognitive Functions of Linguistic Categories in Describing Persons: Social Cognition and Language. Journal of Personality and Social Psychology, 54, 558-568. http://dx.doi.org/10.1037/0022-3514.54.4.558

Semin, G. R., \& Smith, E. R. (1999). Revisiting the Past and Back to the Future: Memory Systems and the Linguistic Representation of Social Events. Journal of Personality and Social Psychology, 76, 877-892. http://dx.doi.org/10.1037/0022-3514.76.6.877

Tanaka, J. W., \& Farah, M. J. (1993). Parts and Wholes in Face Recognition. The Quarterly Journal of Experimental Psychology, 46, 225-245. http://dx.doi.org/10.1080/14640749308401045

Trope, Y., \& Liberman, N. (2000). Temporal Construal and Time-Dependent Changes in Preference. Journal of Personality and Social Psychology, 79, 876-889. http://dx.doi.org/10.1037/0022-3514.79.6.876 
Westerman, D. L., \& Larsen, J. D. (1997). Verbal-Overshadowing Effect: Evidence for a General Shift in Processing. The American Journal of Psychology, 110, 417-428. http://dx.doi.org/10.2307/1423566

Weston, N. J., Perfect, T. J., Schooler, J. W., \& Dennis, I. (2008). Navon Processing and Verbalisation: A Holistic/Featural Distinction. European Journal of Cognitive Psychology, 20, 587-611. http://dx.doi.org/10.1080/09541440701728557

Wickham, L. H., \& Lander, K. (2008). The Effect of Verbal Description and Processing Type on Face Identification. European Journal of Cognitive Psychology, 20, 577-586. http://dx.doi.org/10.1080/09541440701728433

Wyer, N. A., Perfect, T. J., \& Pahl, S. (2010). Temporal Distance and Person Memory: Thinking about the Future Changes Memory for the Past. Personality and Social Psychology Bulletin, 36, 805-816. http://dx.doi.org/10.1177/0146167210370965

Xu, Y., Liu, J., \& Kanwisher, N. (2005). The M170 Is Selective for Faces, Not for Expertise. Neuropsychologia, 43, 588-597. http://dx.doi.org/10.1016/j.neuropsychologia.2004.07.016

Young, A. W., Hellawell, D., \& Hay, D. C. (1987). Configurational Information in face Perception. Perception, 16, 747-759. http://dx.doi.org/10.1068/p160747 